

\title{
Hydrophobic coatings deposited with an atmospheric pressure microplasma jet
}

Andreas Vogelsang, Andreas Ohl, Rüdiger Foest, Karsten Schröder, Klaus-Dieter Weltmann

\section{To cite this version:}

Andreas Vogelsang, Andreas Ohl, Rüdiger Foest, Karsten Schröder, Klaus-Dieter Weltmann. Hydrophobic coatings deposited with an atmospheric pressure microplasma jet. Journal of Physics D: Applied Physics, 2010, 43 (48), pp.485201. 10.1088/0022-3727/43/48/485201 . hal-00574378

\section{HAL Id: hal-00574378 https://hal.science/hal-00574378}

Submitted on 8 Mar 2011

HAL is a multi-disciplinary open access archive for the deposit and dissemination of scientific research documents, whether they are published or not. The documents may come from teaching and research institutions in France or abroad, or from public or private research centers.
L'archive ouverte pluridisciplinaire HAL, est destinée au dépôt et à la diffusion de documents scientifiques de niveau recherche, publiés ou non, émanant des établissements d'enseignement et de recherche français ou étrangers, des laboratoires publics ou privés. 


\title{
Hydrophobic coatings deposited with an atmospheric pressure
}

\section{microplasma jet}

Andreas Vogelsang*, Andreas Ohl, Rüdiger Foest, Karsten Schröder and Klaus-Dieter Weltmann

Leibniz-Institute for Plasma Science and Technology e.V., Felix-Hausdorff-Str. 2, D-17489 Greifswald, Germany

Fax: +49 3834 554301; E-mail: vogelsang@inp-greifswald.de

PACS Number 52

Keywords: micro plasma, plasma jet, thin film, deposition, fluorocarbon, XPS

\begin{abstract}
Successful plasma polymerisation of a fluorocarbon compound $\left(c-\mathrm{C}_{4} \mathrm{~F}_{8}\right)$ using an atmospheric pressure plasma jet is described. The source is operated with argon as working gas at a flow rate of $6 \mathrm{slm}$ and $10-100 \mathrm{sccm}$ admixtures of $\mathrm{c}-\mathrm{C}_{4} \mathrm{~F}_{8}$. Deposition is limited to a discharge regime with strong localization and was observed for conductive substrates only ( $\mathrm{Al}$ and $\mathrm{Si}$ ). The deposition process is characterized by a high local growth rate (40 $\mathrm{nm} / \mathrm{s}$ ) and produces films which show a Teflon-like chemical structure and hydrophobicity. The coatings are characterised using X-ray photo electron spectroscopy (XPS), profilometry, and Scanning electron microscopy (SEM). Changing the ambient atmosphere from protective $\mathrm{N}_{2}$ to normal air only reduces the deposition rate but does not change the chemistry of the film.

Based on the results of parameter variations and the electrical relations of the jet-setup, the special form of the deposition regime of the jet is discussed and considered to be a $\gamma$-mode discharge dependent on the choice of substrate material.
\end{abstract}




\section{Introduction}

Bulk polytetrafluoroethylene (PTFE) has excellent thermal and electrical properties as well as high chemical stability. The surface properties of PTFE, like hydrophobicity, oleophobicity and chemical inertness have particular importance both in food industry and in medical technology. Nowadays fluorocarbon films have many applications ranging from integrated circuits to waterproof coatings of textiles or in biocompatible medical devices ${ }^{[1]}$. Especially the exceptional low surface energy of $\mathrm{CF}_{\mathrm{x}}$ functional groups, which expresses in a very low wettability of the surface, makes it a ideal platform for further surface modifications, such as passivation of biomaterials by albumin ${ }^{[2]}$. To deposit films from C:F monomers, different chemical and physical methods exist. The plasma enhanced chemical vapor deposition (PE-CVD) utilizing low temperature plasma processes is one of the most appealing among these methods, as it allows the treatment of almost any material. For example, Favia et al. ${ }^{[3]}$, deposited hydrophobic films with large water contact angles from a modulated RF glow discharge fed with $\mathrm{C}_{2} \mathrm{~F}_{4}$. PE-CVD is usually performed by high frequency or microwave discharges in the pressure ranges between $10^{-4}$ and 1 mbar. These deposition systems offer plasmas with large-scale volumina and reactive species of long reach, but as there are vacuum systems required, they are expensive and complex. Therefore, atmospheric pressure plasmas have been of increasing interest in the past years. Dielectric barrier discharges (DBD) are among those most used for this purpose ${ }^{[4-6]}$. However, this work focuses on the deposition by means of an atmospheric pressure plasma jet. The plasma source design in comparison to other atmospheric plasma sources is better suited for the precise localized treatment of complex 3D forms, e.g. trenches, inner walls or cavities, as the treated surfaces have not to be placed between the electrodes. The possibility to scale the dimensions of the discharge from centimetres down to the sub millimetre region enhances the applicable options.

Interestingly it appeared, that the deposition of C:F-films from non-thermal jet plasmas is not that simple. First trials with parameters based upon successful deposition experiments of $\mathrm{SiO}_{\mathrm{x}}$ thin films with a jet of similar design ${ }^{[7]}$ and with octafluoropropane $\left(\mathrm{C}_{3} \mathrm{~F}_{8}\right)$ as precursor gas, showed that no deposition could be achieved at all. Neither the admixture of $\mathrm{H}_{2}$ to the ambient $\mathrm{N}_{2}$ atmosphere, nor the change of the monomer to the more widely used octafluorocyclobutane $\left(\mathrm{c}-\mathrm{C}_{4} \mathrm{~F}_{8}\right)$ led to thin film 
formation in the predicted parameter range for afterglow deposition. After increasing the power coupled into the jet and the working gas flow, the active plasma zone was extended and came into contact with the substrate. Surprisingly, only in this case a deposition could be achieved.

The experiments were carried out under two different conditions regarding the ambient gas conditions: first $\mathrm{N}_{2}$ instead of air, as oxygen is known to shift the C:F plasma regime from depositing to etching ${ }^{[8-10]}$, and second normal air, to gain a possible deeper understanding of whether a physical or a chemical mechanism is dominating in this effect.

In this paper results are presented for the first successful deposition of hydrophobic $\mathrm{C}: \mathrm{F}$ thin films with a RF capillary atmospheric pressure microplasma jet. Deposition rate, chemical structure of the film, water contact angle, and the influence of the gaseous surrounding on the deposition process were investigated. Reasons for the deposition behaviour are discussed.

\section{Experimental}

Miniaturized atmospheric pressure plasma jet (APPJ)



Figure 1. Schematic of the basic jet setup. 
The jet device consists of two concentrically arranged capillaries and two cylindrical electrodes (figure 1). The electrodes (stainless steel, width $5 \mathrm{~mm}$, distance $4,5 \mathrm{~mm}$ ) are attached to the outside of the outer quartz capillary $\left(\mathrm{d}_{\text {out }}=6 \mathrm{~mm}, \mathrm{~d}_{\mathrm{in}}=4 \mathrm{~mm}\right)$ thus insulating the discharge from the electrode surface. The RF power is supplied by a Dressler Cesar RF generator, working at $27.12 \mathrm{MHz}$, which is capacitively coupled via a matching network to the upper electrode. The lower electrode, which is connected to ground potential, is arranged $3 \mathrm{~mm}$ above the end of the outer capillary. The monomer is fed into the jet through the inner capillary $\left(\mathrm{d}_{\text {out }}=1.8 \mathrm{~mm}, \mathrm{~d}_{\mathrm{in}}=1.2 \mathrm{~mm}, \mathrm{Al}_{2} \mathrm{O}_{3}\right)$. This design ensures that the monomer gas is introduced downstream of the discharge, which suppresses film deposition inside the jet and minimizes the influence of this feed on the stability of the discharge.

The discharge device is mounted on an aluminium ground plate, in which feedthroughs for gas lines and a vacuum flange are embedded. Connected to the flange are a pressure gauge (CMR 261, Pfeiffer Vacuum GmbH, Germany) and a membrane pump (MD 40, Vacuubrand GmbH, Germany). Upon this construction a glass vessel $\left(\mathrm{d}_{\text {in }} 30 \mathrm{~cm}\right.$, height $\left.42 \mathrm{~cm}\right)$ is placed on an O-ring seal. Thus, by evacuating and purging the set-up a defined ambient atmosphere during the deposition processes is ensured along with a protection against possible toxic reaction products.

\section{Deposition conditions:}

Throughout the experiments, the RF power was varied from $10 \mathrm{~W}$ up to $90 \mathrm{~W}$ (generator output reading). The source was operated with argon (5.0 purity, Linde AG, Germany) as working gas at a flow rate of $6 \mathrm{slm}$ and $10-100 \mathrm{sccm}$ admixtures of $\mathrm{c}_{-} \mathrm{C}_{4} \mathrm{~F}_{8}$ (> 99,99 Mass.\% purity, Air Liquide, Germany). The deposition experiments were carried out with the plasma jet pointing perpendicularly to the samples, which were prepared on a non-grounded support plate at a distance of $4 \mathrm{~mm}$. Squares cut from silicon wafers $(18 \mathrm{~mm} * 18 \mathrm{~mm}, 100$ orientation, p doted, $100 \mathrm{Ohm} / \mathrm{cm}$, University Wafer, USA) and strips of aluminium foil (18 mm * $40 \mathrm{~mm}, 99 \%$ purity, Carl Roth GmbH, Germany) served as substrate. The gases that created the different environmental conditions were $\mathrm{N}_{2}$ (5.0 purity, Linde AG, Germany) and normal air (25\% humidity). Prior to the experiments in $\mathrm{N}_{2}$ environment, the glass 
vessel was evacuated to 50 mbar and purged three times with $\mathrm{N}_{2}$, resulting in a residual oxygen content of about $0.0025 \%$. Afterwards, a flow of $6 \mathrm{slm}$ of the respective gas through the vessel was initiated, to ensure static process conditions. The deposition experiment was preceded by a conditioning step where the plasma was ignited and the monomer admixture was switched on. Only after a delay time of 5 min the deposition started by moving the sample into position under the jet for the duration of the treatment time.

\section{X-ray Photoelectron Spectroscopy (XPS)}

The XPS device used was an Axis Ultra (Kratos, UK) with a conventional hemispherical analyzer. XPS spectra were recorded using a monochromatic $\mathrm{Al} \mathrm{K}_{\alpha}$ source at $1486.6 \mathrm{eV}$ with $150 \mathrm{~W}$ X-ray power in a standard configuration. For the photoelectron spectra of the element content and the highly resolved measurements, the data acquisition parameter were $80 \mathrm{eV}$ and $10 \mathrm{eV}$ pass energy, respectively. Charge compensation was applied. Data acquisition and processing were performed with vision 2.1.3 software (operating software Kratos, UK). XPS spectra were generally recorded for 1s electrons from C, O, N, F, 2p electrons from $\mathrm{Si}$ and 2s electrons from Al. Si and Al signals were taken in order to ensure sufficient thickness of the film. The C1s Peak, C-C and C-H components, was adjusted to $285.0 \mathrm{eV}$. The peak fitting procedure was carried out with the help of CasaXPS software version 2.3.15dev59 (Casa Software Ltd, UK). Gauss-Lorentz (30 \% Lorentz) distribution, Tougaardbaseline, and a fixed FWHM between 1.1 and $1.5 \mathrm{eV}$ were applied. All values referring to the elemental composition are given in XPS atomic-\% and ratios thereof, as $\mathrm{H}$ is not detected by this method.

\section{Water contact angle measurements}

A DIGIDROP (GBX Instrumentation Scientifique, France) was used for the contact angle measurements utilizing the sessile drop method, i.e., a drop of distilled water with a defined volume $(0.5 \mu \mathrm{l})$ was placed onto the horizontally aligned substrate surfaces with the help of a stainless-steel needle of a motorized syringe. The contact angle of the resting drop was determined utilizing the 
computational software of the meter. The values are reproducible within $+/-3^{\circ}$ for repeated preparation and measurement.

\section{Profilometry}

The shown spatial profile of the film thickness was measured by profilometry (Dektak $3^{\text {ST }}$ (Veeco Instruments Inc., USA, stylus force: $30 \mathrm{mg}$, scan velocity $100 \mu \mathrm{m} / \mathrm{s}$ ). An uncoated reference point on the substrate is needed for absolute thickness values. Therefore, the measured samples were partially masked with a film of cellulose acetate prior to the deposition process. Removing the film after deposition leaves a sharp coating edge with a height that is readily measured with a profiler and a scan direction perpendicular to this edge. This method generates only one thickness value at a particular spot per scan. Thus, it is time-consuming to produce a spatial thickness profile, but reduces possible errors caused by a bending of the substrate surface.

\section{Scanning Electron Microscopy (SEM)}

The C:F coatings were inspected with a SEM device (JSM 7500F, Jeol Ltd., Japan) operated in 'gentle beam mode'. This mode utilizes low accelerating voltages thus circumventing the charging up of nonconductive samples. Hence, insulators needn't be sputter-coated with a metal prior to analysis. The resolution of the secondary electron image was about $1.4 \mathrm{~nm}$ for an accelerating voltage of $1 \mathrm{kV}$. The magnification was between $\mathrm{x} 30000$ and $\mathrm{x} 75000$ for a working distance of $4.7 \mathrm{~mm}$. Magnification correction was set to automatic for acceleration voltage and working distance.

\section{Optical Emission Spectroscopy (OES)}

The optical emission of the plasma zone at the substrate was imaged side on through a lens to the entrance of an optical fibre and transferred to a monochromator $(0.5 \mathrm{~m}$ length, grating 2400 lines $/ \mathrm{mm}$, Acton Spectra Pro 2500i, Princeton Instruments, USA). A CCD-Camera (PI-MAX, Princeton Instruments) at the exit port of the monochromator served as detector. The examined spectral range lies between 200 and $400 \mathrm{~nm}$. Exposure times between 10 and $100 \mathrm{~ms}$ with a gain of 100 and 20 accumulations were chosen, depending on the intensity of the discharge. 


\section{Results and Discussion}

Unlike other processes previously reported for jets of this design ${ }^{[7]}$, the deposition takes place only if the plasma plume is in tight contact with the substrate. The jet has to be driven with higher working gas flows compared to the former work ${ }^{[7]}$, and moderate to high powers to achieve these operational conditions. The discharge then develops three spatially relatively immobile filaments, which are in contact with the substrate and give the impression of constricted, high current 'hot' filaments with a high plasma density. They can be adjusted to have equal distance to each other. The deposition process is comparably fast. After only $10 \mathrm{~s}$ the film has reached a thickness sufficient to be visible with the naked eye. The deposition zone is formed by the foot prints of these filaments on the substrate (figure 2). A spatial profile of the foot print was measured by profilometry. Figure 3 shows the profile along a line crossing two of the three deposition patches. As can be seen, a maximum film thickness of $7.8 \mu \mathrm{m}$ after $180 \mathrm{~s}$ of deposition was achieved, which leads to a local deposition rate of $43 \mathrm{~nm} / \mathrm{s}$ for treatment in $\mathrm{N}_{2}$ atmosphere. Because of this very inhomogeneous deposition profile, the quantification of the deposition rate is presented as mass difference $(\mu \mathrm{g} / \mathrm{s})$ instead of film growth rate $(\mathrm{nm} / \mathrm{s})$.

It has been pointed out ${ }^{[7]}$, that films deposited locally with jet plasmas tend to display local variations in their chemical structure, for example attributed to turbulences or inhomogeneous plasma conditions ${ }^{[11]}$. Hence, XPS scans along a line across the sample were carried out in order to substantiate a present axial and azimuthal variation in chemical composition and structure for the films reported here, too. 



Figure 2. Example for growth of C:F films: photograph showing deposition pattern caused by localized filaments on aluminium (left), micrograph with a top view of the deposition pattern on silicon (right).

Scans were recorded for three different samples treated in $\mathrm{N}_{2}$ atmosphere. The distance between measurement points was $0.5 \mathrm{~mm}$. Figure 4 shows a typical example of these measurements. Except for the outer, small boundary region, where the elemental composition is determined mainly by silicon (45\%) from the substrate which is sensed through the film and less fluorine (5\%) content, the chemical composition of the main diameter of the deposition foot print itself remains practically constant, independent on the film thickness. The films are mainly constituent of fluorine $(60 \%)$ and carbon (40\%), with small contributions of oxygen (1.5\%) just above the detection limit. With this local distribution in mind, further XPS analyses could be restricted to four points per film only. The results were averaged and the standard deviation is given as error bar. 




Figure 3. Spatial profile of thickness of a C:F polymer film, $60 \mathrm{~W}, 4 \mathrm{~mm}$ distance, $180 \mathrm{~s}$ treatment time, $\mathrm{N}_{2}$ atmosphere.



Figure 4. XPS linescan of a C:F film on silicon substrate, $60 \mathrm{~W}, 4 \mathrm{~mm} 180 \mathrm{~s}$ treatment time, $\mathrm{N}_{2}$ atmosphere. 
The desired main property of the coating is hydrophobicity, thus the wettability of the surface was determined by static water contact angle measurements. Values between $100^{\circ}$ and $135^{\circ}$ were obtained depending on the film thickness. In the middle of the sample the value was lower than on the deposition maxima. SEM photographs (figure 5) can facilitate the interpretation of this observation. The microstructure of the thinner film is in the range of $100 \mathrm{~nm}$, whereas it is in the range of micrometres in the area of the deposition maxima. It is supposed that this increased roughness further enhances the basic hydrophobic properties of the coating ${ }^{[12,13]}$ and can create the so called super hydrophobic surfaces with contact angles approaching $180^{\circ}$.



Figure 5. SEM pictures of a C:F coating, thin film in the middle of the substrate (left), thick film at a deposition maximum (right).

The applied power can have a strong effect on the fragmentation of the monomer and hence on the crosslinking of the thin film ${ }^{[14,9]}$. Experiments with different rf powers and fixed working gas flow and sample distance were carried out on aluminium substrates to quantify this effect. Nevertheless, with the exception of low powers (10 W and $20 \mathrm{~W}$ ) the chemical composition remains unaffected by varying rf power (figure 6). 


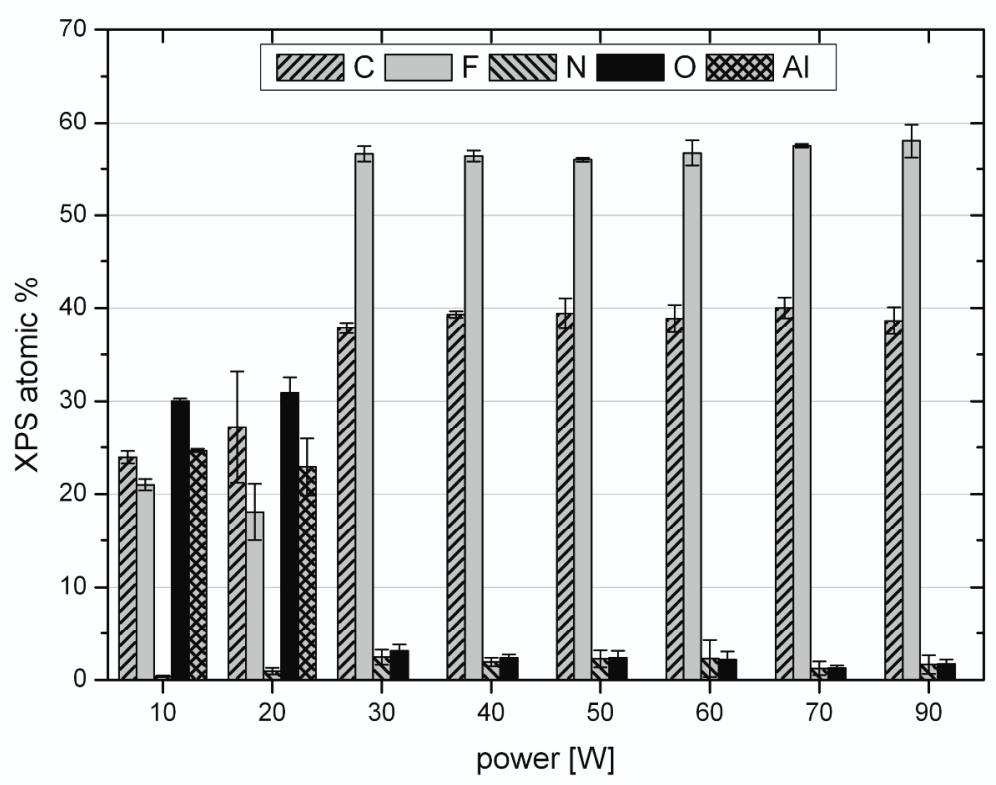

Figure 6. XPS atomic percentage for different applied $\mathrm{rf}$ powers, aluminium substrate, $4 \mathrm{~mm}$ distance, $180 \mathrm{~s}$ treatment, $\mathrm{N}_{2}$ atmosphere.

The deviation at low powers can be explained by evaluating the fits for the highly resolved measured $\mathrm{C} 1 \mathrm{~s}$ peak (figure 7). It demonstrates, that the existing carbon is bound to oxygen and that no $\mathrm{CF}_{2}$ - or $\mathrm{CF}_{3}$-bindings are found. This indicates that all of the detected fluorine is directly bound to the aluminium surface forming aluminium fluoride $\left(\mathrm{AlF}_{3}\right)$. 


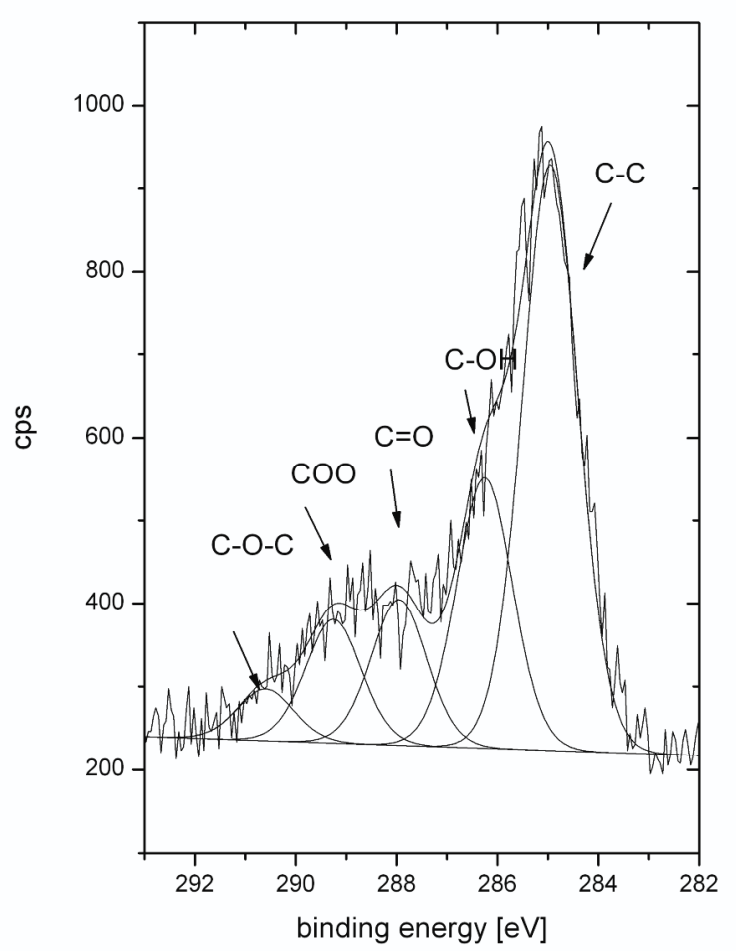

Figure 7. XPS: Fit of a highly resolved measured C 1s peak for $20 \mathrm{~W}$.

As existing $\mathrm{CF}_{\mathrm{x}}$-radicals reaching the sample surface would most probably form a thin film another reaction path has to be found to explain the creation of $\mathrm{AlF}_{3}$ and thus the fluorine content on the surface.

The presence of oxygen in the plasma, even under $\mathrm{N}_{2}$ environment, caused by working under atmospheric pressure conditions and the layer of oxidized aluminium on the surface, enables reaction channels that lead to the creation of carbonic fluorides $\left(\mathrm{COF}_{\mathrm{x}}\right)$, through many reactions originating from different fragments of $\mathrm{C}_{4} \mathrm{~F}_{8}$, which are reviewed in ${ }^{[15]}$, for example:

$$
\begin{aligned}
& \mathrm{C}_{2} \mathrm{~F}_{4}+\mathrm{O} \rightarrow \mathrm{COF}_{2}+\mathrm{CF}_{2} \\
& \mathrm{CF}_{3}+\mathrm{O}_{2} \rightarrow \mathrm{COF}_{3}+\mathrm{O} \\
& \mathrm{CF}_{3}+\mathrm{O} \rightarrow \mathrm{COF}_{2}+\mathrm{F} \\
& \mathrm{CF}_{2}+\mathrm{O}_{2} \rightarrow \mathrm{COF}_{2}+\mathrm{O}
\end{aligned}
$$




$$
\begin{aligned}
& \mathrm{CF}_{2}+\mathrm{O} \rightarrow \mathrm{COF}+\mathrm{F} \\
& \mathrm{CF}+\mathrm{O}_{2} \rightarrow \mathrm{COF}+\mathrm{O}
\end{aligned}
$$

These molecules then react with the aluminium surface, forming AlF with various byproducts.

The main intermediates in this reaction scheme are $\mathrm{CF}_{2}, \mathrm{CF}_{3}, \mathrm{CF}, \mathrm{COF}$ and $\mathrm{AlF}$, the resulting stable products $\mathrm{CF}_{4}, \mathrm{COF}_{2}, \mathrm{CO}, \mathrm{CO}_{2}$ and $\mathrm{AlF}_{3}$. The summarized reaction scheme is given by:

$$
\left(\mathrm{C}_{2} \mathrm{~F}_{4}\right)_{\mathrm{n}}+\mathrm{O}_{2}+\mathrm{Al} \rightarrow \mathrm{AlF}_{3}+\mathrm{CO}+\mathrm{CO}_{2}
$$

As the presence of water cannot be neglected, another reaction leading to $\mathrm{AlF}_{3}$ is possible:

$$
\begin{aligned}
& \mathrm{CF}_{4}+\mathrm{H}_{2} \mathrm{O} \rightarrow \mathrm{COF}_{2}+2 \mathrm{HF} \\
& \mathrm{COF}_{2}+\mathrm{H}_{2} \mathrm{O} \rightarrow \mathrm{CO}_{2}+2 \mathrm{HF} \\
& \mathrm{Al}_{2} \mathrm{O}_{3}+6 \mathrm{HF} \rightarrow 2 \mathrm{AlF}_{3}+3 \mathrm{H}_{2} \mathrm{O}
\end{aligned}
$$

The most interesting effect here is, that only above $30 \mathrm{~W}$ a deposition occurred, which is indicated by the vanishing of the aluminium signal and the rise of the fluorine and carbon content. For even higher powers the content of elements changes only in the range of 1-2\%. The composition of the coating and also the degree of crosslinking is therefore independent on the power coupled into the jet, as can be seen in figure 9. This whole behaviour is due to the fact that for higher powers the active plasma zone of the jet is extended and at $30 \mathrm{~W}$ comes into contact with the substrate. At this point the discharge contracts itself, the deposition starts and the filaments form the three deposition patches.

This behaviour resembles a transition from $\alpha$ - to $\gamma$-mode for the discharge zone between orifice of the jet and substrate surface. In fact, many similarities can be found. The $\alpha$-mode is prevailing in the effluent plasma of the (capacitively) coupled rf capillary discharge. When this mode suddenly changes to $\gamma$-mode at about $30 \mathrm{~W}$, the substrate would become the grounded electrode and the jet plasma the 'driven electrode', respectively. This discontinuous transition of the modi was first observed in moderate pressure rf-discharges and calculated for these parameters by Raizer et al ${ }^{[16]}$. For discharges 
at atmospheric pressure an expansion of these calculations was reported by Odrobina and Kando ${ }^{[17]}$. They too found a similar behaviour of the transition and calculated that for an argon discharge and a secondary electron emission coefficient of 0.01 such a discontinuous form of transition would be possible, as long as the applied frequency satisfied the condition:

$f / p<f_{c r}(\gamma)$

with $\mathrm{f}_{\mathrm{cr}}=300 \mathrm{kHz} /$ Torr. The discharge in this work with $\mathrm{f} / \mathrm{p}=35.68 \mathrm{kHz} /$ Torr remains well within this range for $\mathrm{P}=760$ Torr and $\mathrm{f}=27.12 \mathrm{MHz}$. This discontinuous transition was also observed for an atmospheric pressure rf-discharge in Helium ${ }^{[18,19]}$.

Other characteristics of a $\gamma$-mode can be concluded from the successful and fast deposition process after the transition, like the local increase of power density near the electrode surface (in this case the substrate) and an increase of electron density in the near surface region by up to an order of magnitude, which are the most probable causes for an increased concentration of very reactive and thus short lived $\mathrm{CF}_{\mathrm{x}}$-radicals, which as they are created in close vicinity to the substrate can polymerise fast.

Based on the reaction mechanisms proposed for the fluorination of aluminium one could assume that an increased concentration of $\mathrm{CF}_{\mathrm{x}}$-radicals caused by the higher power density would just result in a preferential formation of volatile components like $\mathrm{COF}_{\mathrm{x}}, \mathrm{CO}_{2}$, etc. instead of polymerisation, as these are the main competing channels to the polymerisation reaction. The simplified reaction schemes are as follows:

$$
\begin{aligned}
& \mathrm{CF}_{\mathrm{x}}+\mathrm{CF}_{\mathrm{x}} \rightarrow\left(\mathrm{C}_{\mathrm{y}} \mathrm{F}_{\mathrm{z}}\right)_{\mathrm{n}}(\text { Polymerisation) } \\
& \mathrm{CF}_{\mathrm{x}}+\mathrm{O}, \mathrm{H}_{2} \mathrm{O} \rightarrow \mathrm{COF}_{\mathrm{x}}, \mathrm{CO}_{2} \text {, etc. (Volatile components) }
\end{aligned}
$$


The summarized reactions indicate that the polymerisation reaction runs roughly quadraticly with $\mathrm{C}_{\mathrm{CFx}} * \mathrm{C}_{\mathrm{CFx}} * \mathrm{R}_{\mathrm{pol}}$, whereas the competing channel only runs linearly with $\mathrm{C}_{\mathrm{CFx}} * \mathrm{C}_{\mathrm{O}, \mathrm{H} 2 \mathrm{O}} * \mathrm{R}_{\mathrm{vol}}$, which results in a net thin film forming.

Evidence for the existence of $\mathrm{CF}_{\mathrm{x}}$-radicals during the deposition was provided by complementary conducted optical emission spectroscopy of the active plasma zone on the substrate. The detected emission in the range from 200 to $360 \mathrm{~nm}$ (figure 8) can be allocated to $\mathrm{CF}(220-265 \mathrm{~nm})^{[20,21]}, \mathrm{CF}_{2}$ and $\mathrm{CF}_{2}{ }^{+}(240-360 \mathrm{~nm})^{[22,23]}, \mathrm{OH}(300-320 \mathrm{~nm})^{[22]}$ and the $2^{\text {nd }}$ pos. system of $\mathrm{N}_{2}(330-460 \mathrm{~nm})$ $[22]$.



Figure 8. Optical emission spectrum of the deposition process, $60 \mathrm{~W}, \mathrm{~N}_{2}$ atmosphere. 



Figure 9. XPS: Comparison of the fits of highly resolved measured C 1s peaks for different powers, 30 W (left) and $90 \mathrm{~W}$ (right).

As main parts of the $\mathrm{C} 1 \mathrm{~s}$ peak of the thin film, the termination element $\mathrm{CF}_{3}$, the chain element $\mathrm{CF}_{2}$ and the crosslinking elements $\mathrm{CF}, \mathrm{C}-\mathrm{CF}, \mathrm{CF}-\mathrm{CF}$ and $\mathrm{C}-\mathrm{C}$ were fitted ${ }^{[9]}$. The contribution of $\mathrm{CF}_{2}$ and $\mathrm{CF}_{3}$ amounts to $32 \%$ and $18 \%$, respectively. This indicates a short chain structure, as for each two chain links one termination element exists. The total amount of all crosslinking elements is $40 \%$ and independent of the deposition power. 


\begin{tabular}{cccc}
\hline Peak & binding energy $[\mathrm{eV}]$ & $\%$ area $[30 \mathrm{~W}]$ & $\%$ area $[90 \mathrm{~W}]$ \\
\hline$\underline{\mathrm{C}}-\mathrm{C}, \mathrm{C}-\mathrm{H}$ & 285.0 & 2.91 & 1.23 \\
$\underline{\mathrm{C}}-\mathrm{CF}$ & 287.1 & 12.01 & 14.13 \\
$\underline{\mathrm{C}}-\mathrm{CF} \mathrm{F}_{\mathrm{x}}$ & 288.1 & 3.21 & 3.30 \\
$-\underline{\mathrm{CF}}$ & 289.6 & 21.01 & 22.46 \\
$\underline{\mathrm{C}}-\mathrm{CF}$ & 290.6 & 7.27 & 6.69 \\
$-\underline{\mathrm{CF}}_{2}$ & 291.8 & 32.22 & 32.13 \\
$\underline{\mathrm{C}} \mathrm{F}_{2}-\mathrm{O}$ & 292.8 & 2.74 & 1.32 \\
$-\underline{\mathrm{CF}}_{3}$ & 293.9 & 18.63 & 18.72 \\
\hline
\end{tabular}

Table 1. XPS: Fitted components of the $\mathrm{C}$ 1s Peaks, their respective binding energies and percentage of area for the two peaks at different applied powers.

Deposition with different treatment times was carried out as another approach for a possible variation of surface properties. Additionally, these experiments were carried out for air as ambient atmosphere. Despite the fact that the oxygen content during the deposition process is about four orders of magnitude higher then for the experiments at $\mathrm{N}_{2}$ environment, no noticeable change in the film composition was observed. The content of elements is comparable to the deposition with $\mathrm{N}_{2}$ atmosphere and varies only in the range of one percent. 




Figure 10. XPS atomic percentage for different treatment times and environment (air or $\mathrm{N}_{2}$ ) (silicon substrate, $60 \mathrm{~W}, 4 \mathrm{~mm}$ distance).

However, the differences in the deposition rate show clearly the influence of the oxygen. Figure 11 shows the respective time dependencies. For the treatment with $\mathrm{N}_{2}$ environment it rises from $0.5 \mu \mathrm{g} / \mathrm{s}$ for $10 \mathrm{~s}$ treatment time up to $2.0 \mu \mathrm{g} / \mathrm{s}$ for times of $60 \mathrm{~s}$ and longer. The overall deposition rate drops about half an order, when the ambient atmosphere is air. After a rise of the rates within the first $60 \mathrm{~s}$, which we attribute to substrate heating, stationary conditions are obtained. These allow the comparison of the processes. Interestingly, the air atmosphere does not reduce the $\mathrm{CF}_{\mathrm{x}} / \mathrm{F}$ ratio enough to inhibit deposition completely. This might be a result of the comparatively high working gas flow, which can effectively keep the oxygen away from the deposition process.

As stated before, the deposition profile is very inhomogeneous, but assuming a homogeneous film thickness with an area of $1 \mathrm{~cm}^{2}$ and an average density of $1 \mathrm{~g} / \mathrm{cm}^{3}$ a growth rate of $12 \mathrm{~nm} / \mathrm{s}$ can be derived from the maximum mass deposition rate of $2 \mu \mathrm{g} / \mathrm{s}$. 




Figure 11. Mass deposition rate for different treatment times, aluminium substrate, $60 \mathrm{~W}, 4 \mathrm{~mm}$ distance.

The results shown up to now describe an astonishingly robust process. Neither increase of applied rf power by up to $300 \%$, nor increase of treatment time or the deposition at air, alters the composition or degree of crosslinking of the coating in a significant way. It seems that the contraction of the glow discharge, the forming of filaments with high energy density on the substrate, i.e. direct plasma contact, and a stable footprint are the decisive factors for the deposition conditions. A physical explanation for these effects shall be given here using the equivalent circuit diagram of the discharge. 




Figure 12. Equivalent circuit diagram of the system jet - substrate.

The circuit diagram of the system of jet and substrate shows a simplified scheme of the main components that contribute to the electric relations and is given in figure $12 . \mathrm{C}_{1}$ and $\mathrm{C}_{2}$ are formed by the sum of the capacitances of the dielectric barrier and the plasma sheath, and are determined as of the same dimension. $R_{1}$ and $R_{2}$ are the resistances of the respective plasma zones between the electrodes and between jet orifice and substrate surface, whereas $R_{3}$ is the resistance of the substrate. $\mathrm{C}_{3}$ is the series connection of the capacitances of the plasma sheath on the substrate, the substrate itself and the stray capacitance between substrate and ground.

All decisive elements can be calculated or directly measured. The capacitances $C_{1}$ and $C_{2}$ are calculated as cylindrical capacitors with either thickness of the capillary or debye length as width. For 
an average electron density of $3 * 10^{13} \mathrm{~cm}^{-3}$ and an electron temperature of $2 \mathrm{eV}$, the debye length is calculated as $1.9 \mu \mathrm{m}$, which leads to a capacitance of the plasma sheath in the range of $300 \mathrm{pF}$. The upstream connected capacitance of the dielectric is $2.5 \mathrm{pF}$, so that $\mathrm{C}_{1}$ and $\mathrm{C}_{2}$ are both about $2.48 \mathrm{pF}$. $\mathrm{C}_{3}$ is dominated by the stray capacitance which was measured to be $1.9 \mathrm{pF}$. The value for the aluminium substrate is some $10 \mathrm{pF}$ and for the plasma sheath on the sample again about $300 \mathrm{pF}$.

The stray capacitance forms an impedance of about $3 * 10^{3} \Omega$ for the frequency used in these experiments and thus is large enough to allow a charge flow. This offers the potential for the discharge to contract itself on the substrate if the resistance of the substrate $R_{3}$ (contact resistance) is not too high. Indeed, during experiments with silicon substrates an effective RF potential of about $150 \mathrm{~V}$ on the substrate was measured. If one assumes an average diameter of a filament of $0.1 \mathrm{~mm}$ and a resistance of the contact area on the silicon substrate of about $0.1 \Omega$, a current density of about $6^{*} 10^{2}$ $\mathrm{A} / \mathrm{cm}^{2}$ can be derived. This current density characterises the discharge as diffuse arcing ${ }^{[24]}$. An even higher current density can be assumed for aluminium with a resistance in the range of $10^{-6} \Omega$. In contrast, the resistance of a polystyrene substrate is about $10^{10} \Omega$ and thus too high to allow such an effect. Hence, the choice of substrate material does influence the potential of the jet to form a discharge regime capable of deposition and the energy density of the filament. Please note that, the exact geometric factors of the contact resistance are not taken into account and the substrate resistances were roughly approximated using the specific resistance of the material and the thickness of the respective substrate. Therefore the values rather represent upper limits and their exact values are most likely smaller. This hypothesis is supported by the observations made during experiments with different substrates and is in concordance with the observed power dependency of the deposition rates. These rates are generally higher for aluminium than for silicon (figure 13). With polystyrene substrates no deposition could be achieved at all. Furthermore, it can be assumed from the progression of the curves that the monomer deficient regime is reached in the case on an aluminium substrate. For silicon this is not case, which is in accordance to the proposed model. 




Figure 13. Mass deposition rate for different jet powers and substrates, $4 \mathrm{~mm}$ distance, $180 \mathrm{~s}$ treatment time, $\mathrm{N}_{2}$ atmosphere.

\section{Conclusion}

Conditions were discovered to deposit C:F-films with an atmospheric pressure plasma jet. The dependencies from parameters like power or treatment time were investigated. Additionally the impact of the ambient atmosphere on this process was evaluated by using $\mathrm{N}_{2}$ and air environment. The deposition regime found provides very high film growth rates (up to $43 \mathrm{~nm} / \mathrm{s}$ with $\mathrm{N}_{2}$ atmosphere) and creates coatings with a distinctive deposition pattern. The chemical composition and structure was determined by XPS and found to be laterally homogeneous, with a $[\mathrm{F}] /[\mathrm{C}]$ of about 1.4 and a very low content of nitrogen and oxygen. Fits of the highly resolved measured $\mathrm{C} 1 \mathrm{~s}$ peak show a degree of crosslinking of about $40 \%$ and a $\left[\mathrm{CF}_{2}\right] /\left[\mathrm{CF}_{3}\right]$ of about 1.8. The static water contact angle for these films was determined to be in the range of $100^{\circ}$ to $135^{\circ}$. The use of normal air as ambient atmosphere has no impact on the film chemistry, but reduces the deposition rate by a factor of four.

The formation of a special discharge regime, namely the constricted and localized arc-like discharge, is mandatory to deposit C:F films with this device. The discharge mode is considered to be an atmospheric pressure $\gamma$-mode discharge with the substrate acting as second grounded electrode. 
However, prerequisite is a sufficient conductivity of the substrate. A simplified scheme of the electric properties of the system jet - substrate is given which clarifies the observed dependence of the discharge regime on the choice of substrate material.

Regarding the useful Teflon-like film properties and very high local growth rates, it would be interesting to further investigate this discharge regime to identify setups resulting in a practically useful deposition pattern.

\section{References}

[1] Milella A, Palumbo F, Favia P, Cicala G and d'Agostino R 2004 Plasma Process. Polym. 1 164-70

[2] Elbert D L and Hubbell J A 1996 Annu. Rev. Mater. Sci. 26 365-94

[3] Favia P, Cicala G, Milella A, Palumbo F, Rossini R and d'Agostino R 2003 Surf. Coat. Technol. 169 609-12

[4] Borcia G and Brown N M D 2007 J. Phys. D: Appl. Phys. 40 1927-36

[5] Heyse P, Dams R, Paulussen S, Houthofd K, Janssen K, Jacobs P A and Sels B F 2007 Plasma Process. Polym. 4 145-57

[6] Vinogradov I P and Lunk A 2005 Surf. Coat. Technol. 200 695-9

[7] Schäfer J, Foest R, Quade A, Ohl A and Weltmann K D 2008 J.Phys D: Appl. Phys. 41

[8] Coburn J W and Winters H F 1979 J. Vac. Sci. Technol. 16 1613-4

[9] D'Agostino R 1990 Plasma deposition, treatment, and etching of polymers (Boston: Academic Press)

[10] Oehrlein G S, Zhang Y, Vender D and Haverlag M 1994 J. Vac. Sci. Technol. 12 32332

[11] Benedikt J, Raballand V, Yanguas-Gil A, Focke K and von Keudell A 2007 Plasma Phys. Control. Fusion 49 B419-B27

[12] Cassie A B D and Baxter S 1944 Trans. Farad. Soc. 40 0546-50

[13] Wenzel R N 1936 Ind. Eng. Chem. 28 988-94

[14] Yasuda H 1985 Plasma polymerization (Orlando: Academic Press)

[15] Losada M and Chaudhuri S 2009 J. Phys. Chem. A 113 5933-41

[16] Raizer I U P, Shneider M N and Yatsenko N A 1995 Radio-frequency capacitive discharges (Boca Raton: CRC Press)

[17] Odrobina I and Kando M 1996 Plasma Sources Sci. Technol. 5 517-22

[18] Yang X, Moravej M, Nowling G R, Babayan S E, Panelon J, Chang J P and Hicks R F 2005 Plasma Sources Sci. Technol. 14 314-20

[19] Yang X W, Moravej M, Nowling G R, Chang J P and Hicks R F 2005 IEEE Trans. Plasma Sci. 33 294-5

[20] Millard M M and Kay E 1982 J. Electrochem. Soc. 129 160-5

[21] Cruden B A, Gleason K K and Sawin H H 2002 J. Appl. Phys. 91 9547-55

[22] Pearse R W B and Gaydon A G 1976 The identification of molecular spectra (London: Chapman and Hall)

[23] King D S, Schenck P K and Stephenson J C 1979 J. Mol. Spectrosc. 78 1-15

[24] Raizer I U P 1991 Gas discharge physics (Berlin: Springer-Verlag) 